\title{
Effectiveness of Essential Health Care Services Delivery in Nepal
}

\author{
Devkota $B^{1}$ \\ ${ }^{1}$ Tribhuvan University, Kathmandu, Nepal
}

\begin{abstract}
Background: Ensuring delivery of quality health services in a sustainable and equitable manner is a challenge in Nepal. A host of factors may have impeded the access, quality and utilization of the health services particularly by the marginalized and disadvantaged sections of the population. Review essential health care services (EHCS) provided by the public health facilities, level of progress, effectiveness, sustainability, equity and efficiency, quality of care and inclusion of marginalized and disadvantaged populations in health care services

Methods: A total of 40 VDCs from 10 districts representing five regions and three eco-zones were covered. Altogether 800 mothers with under two year children, 40 health service providers, 145 key informants and 40 exit clients were interviewed. Forty focused group discussions were also conducted. From each district, health records of one hospital, PHCC, HP, SHP and Ayurvedic health facility each were collected.

Results: More than two-third (68.2\%) of the mothers received antenatal checks, highest in hills (85\%) followed by terai $(64.5 \%)$ and mountain districts (52.8\%). Tetanus vaccine coverage (80.7\%) seems higher compared to Nepal Demographic Health Survey 2001 (45\%). FP use rate in mountain, hill and terai are $57.6 \%, 54.1 \%$ and 49.7\%, higher than in DoHS 2003/2004 statistics, which were 26.8\%, 36.4\% and 45.3\% respectively. Nine out of ten patients visiting the health facilities were outpatients. The coverage of DPT 3, Polio 3, BCG and measles are $92.8 \%$, 93.4\%, 95.2\% and 90.7\% respectively. From the service utilization perspective, disparities in terms of gender, ecological regions, season of the year and health facility were revealed.

Conclusion: Health sector services are yet to be made responsive to the ecological and district specific health problems, and be made more inclusive linking with doable safety nets.

Key words: Essential health care services, effectiveness, sustainability, equity and efficiency, quality of care and inclusion
\end{abstract}

\section{INTRODUCTION}

The Government of Nepal, through its policy papers like Poverty Reduction Strategy Paper (PRSP), Agenda for Reform (2004), Health Sector Programme
Implementation Plan (2003), National Health Sector Programme-Implementation Plan (2004-2009), the Local Self Governance Act (1998), Medium Term Expenditure Framework (2002), Millennium Development Goals

Correspondence: Bhimsen Devkota, Tribhuvan University, Kathmandu, Nepal. Phone:+97714362330, Email: bdevkota@abdn.ac.uk 
(MDGs) and the current development plans, has expressed its commitments for improved and equitable allocation of resources, increased empowerment, inclusion and partnerships. The health sector programs aim to meet the health and welfare needs of all, especially the poor, women and other vulnerable groups and encourage a move away from project towards a more programmatic, sector-wide approach, in order to deliver health services in a more sustainable and equitable manner. ${ }^{1,2}$ At present MoHP has defined 20 key service interventions under the Essential Health Care Services (EHCS) and made concerted efforts to allocate its resources for equitable and accessible health services throughout the country.

However maintaining equitable access to quality health services still pose a challenge due to many reasons. The coverage of health services has fluctuated over the years with improvement in some programs and stagnation in many. This evaluation study was carried out to; review the essential health services provided by public health facilities, assess the level of progress, effectiveness, sustainability and continuity of EHCS, equity and efficiency, quality of care from the client and provider perspectives, and inclusion of marginalized and disadvantaged populations in accessing the health care services.

\section{METHODS}

The study had drawn sample from the cross section of the entire country; five regions and three eco-zones. Solukhumbu, Jhapa, Parsa, Lalitpur, Mustang, Kaski, Surkhet, Dang, Doti and Kanchanpur districts were included in the study.

A total of 40 VDCs, 4 VDCs from a district, two from urban and two from rural areas were selected. Altogether 800 households, 20 households from a VDC, were covered for the household interviews.

The methods of data collection included; individual indepth interviews (800 mothers having under 2 years' children and 40 health service providers), Key informants interviews (145 interviews in total comprising District health personnel, community gate keepers, NGO representatives and central level key informants), 104 exit client interviews, 40 Focused Group Discussions ( 20 with community people, 10 with health workers and 10 with Health Facility Management Committees), health records review from one hospital, one PHCC, one HP, one SHP and one Ayurvedic health facility over the years 2000-2005.
The tools and methodology of the study was pre-tested in Bhaktapur and Kavrepalanchowk districts. Informed consents of the participants were taken before preceding the study and their anonymity and confidentiality was strictly maintained.

The quantitative data for the study was analyzed by using SPSS software. The qualitative data was analyzed manually under different themes using the "question routes".

\section{RESULTS}

The results of the study have been presented following the study objectives.

\section{EHCS Delivered and Progress and Achievements Made}

The coverage of main health service interventions; safe motherhood, family planning, outpatient care and child health are presented below.

\section{Safe motherhood}

The trend of first ANC visit as percentage of expected pregnancies seems on the rise in seven districts (Dang, Surkhet, Parsa, Kaski, Kanchapur, Lalitpur and Doti districts) and it is fluctuating in other three districts (i.e. Solukhumbu, Mustang and Jhapa). Delivery attendance by skilled health workers is also on track in half of the districts but the progress is with very low pace (10 $20 \%)$. However in two districts, Parsa and Doti, skilled birth attendance rates are $41 \%$ and $43 \%$ respectively.

The coverage of tetanus (TT) vaccines $(80.7 \%)$ seem higher compared to the Nepal Demographic Health Survey (NDHS) 2001 (45\%). ${ }^{3}$ The present survey finding has shown higher coverage of TT vaccine in mountain (58.9\%), hill (87.5\%) and Terai (85.5\%) regions in comparison to Department of Health Services (DoHS) records 2003/2004 i.e. $20.3 \%, 28.3 \%$ and $58.8 \%$ respectively.

Similarly $68.2 \%$ mothers have received antenatal (ANC) checks, which is highest in hills $(85 \%)$ followed by terai $(64.5 \%)$ and mountain districts $(52.8 \%)$. The NDHS 2004/2005 shows $9 \%$ deliveries occurred at home. This survey shows higher proportion of institutional deliveries, 40.3\% at hospital and health center and $2.6 \%$ at private clinics and nursing homes. However, home delivery is substantially higher yet in all three ecological regions, $\mathbf{7 6 . 1 \%}$ in mountain $55.6 \%$ in Terai and $42.9 \%$ in hill. 


\begin{tabular}{|c|c|c|c|c|c|c|c|c|c|c|}
\hline \multirow{3}{*}{ Place of Birth last child } & \multicolumn{10}{|c|}{ Caste/Ethnicity } \\
\hline & \multicolumn{2}{|c|}{ Brahmin/ Chhetri } & \multicolumn{2}{|c|}{ Newar/ Janajati } & \multicolumn{2}{|c|}{ Muslim and others } & \multicolumn{2}{|c|}{ Dalit } & \multicolumn{2}{|c|}{ Total } \\
\hline & $\mathrm{N}$ & $\%$ & $\mathrm{~N}$ & $\%$ & $\mathrm{~N}$ & $\%$ & $\mathrm{~N}$ & $\%$ & $\mathrm{~N}$ & $\%$ \\
\hline Hospital/ Health centre & 133 & 45.1 & 117 & 37.3 & 19 & 67.9 & 58 & 33.3 & 327 & 40.3 \\
\hline Private nursing home & 11 & 3.7 & 9 & 2.9 & 0 & 0 & 1 & 0.6 & 21 & 2.6 \\
\hline Home & 149 & 50.5 & 184 & 58.6 & 9 & 32.1 & 112 & 64.4 & 454 & 56.0 \\
\hline Others & 2 & 0.7 & 4 & 1.3 & 0 & 0 & 3 & 1.7 & 9 & 1.1 \\
\hline Total & 295 & 100 & 314 & 100 & 28 & 100 & 174 & 100 & 811 & 100 \\
\hline
\end{tabular}

Ethnicity wise, it is Dalits who have least institutional deliveries (33.3\%), which is $37.3 \%$ among Newar and Janajati and $45 \%$ among Brahmin/Chhetri.

\section{Table 2. Personnel who assisted last delivery}

\begin{tabular}{|lccccccc|} 
Personnel who assisted & \multicolumn{7}{c}{ Geographical regions } \\
last delivery & \multicolumn{2}{c}{ Mountain } & \multicolumn{2}{c}{ Hill } & \multicolumn{2}{c|}{ Terai } \\
& $N$ & $\%$ & $N$ & $\%$ & $N$ & $\%$ & Total N (\%) \\
\hline MCHW & 5 & 3.2 & 11 & 4.7 & 4 & 1.1 & $20(2.6)$ \\
FCHV & 18 & 11.5 & 10 & 4.3 & 29 & 7.5 & $57(7.4)$ \\
Nurse/ ANM & 23 & 14.6 & 36 & 15.5 & 75 & 19.6 & $134(17.3)$ \\
Doctor/HA/AHW & 18 & 11.5 & 88 & 37.8 & 92 & 24.1 & $198(25.6)$ \\
Mothers- in- law & 44 & 28.0 & 63 & 27.0 & 150 & 39.3 & $257(33.3)$ \\
Friends & 29 & 18.4 & 22 & 9.4 & 22 & 5.8 & $73(9.5)$ \\
Others & 20 & 12.8 & 3 & 1.3 & 10 & 2.6 & $33(4.3)$ \\
Total & 157 & 100.0 & 233 & 100.0 & 382 & 100.0 & $772(100.0)$ \\
\hline \hline
\end{tabular}

Still one third of the deliveries (33.3\%) are assisted by mothers-in-law; highest in terai (39.3\%) than in hill (27\%) and mountain (28\%).

\section{Family Planning}

Current FP use rate in mountain, hill and terai are $57.6 \%$, $54.1 \%$ and $49.7 \%$, higher than in DoHS 2003/2004 statistics which were $26.8 \%, 36.4 \%$ and $45.3 \%$ respectively. ${ }^{4}$

\begin{tabular}{|c|c|c|}
\hline \multirow{2}{*}{$\begin{array}{l}\text { Geographical } \\
\text { regions }\end{array}$} & \multicolumn{2}{|c|}{ FP devices used } \\
\hline & $\begin{array}{c}\text { EHCSD Survey, } \\
2006\end{array}$ & $\begin{array}{l}\text { CPR , DoHS, } \\
2003 / 2004\end{array}$ \\
\hline Mountain & 57.6 & 26.8 \\
\hline Hill & 54.1 & 36.4 \\
\hline Terai & 49.7 & 45.3 \\
\hline Total & 52.7 & 40.0 \\
\hline
\end{tabular}

The FP use seems among Dalits is $25 \%$, which is little more among Brahmins (28\%). Hospitals (62.6\%) and health post seem the principal outlets for the FP devices.

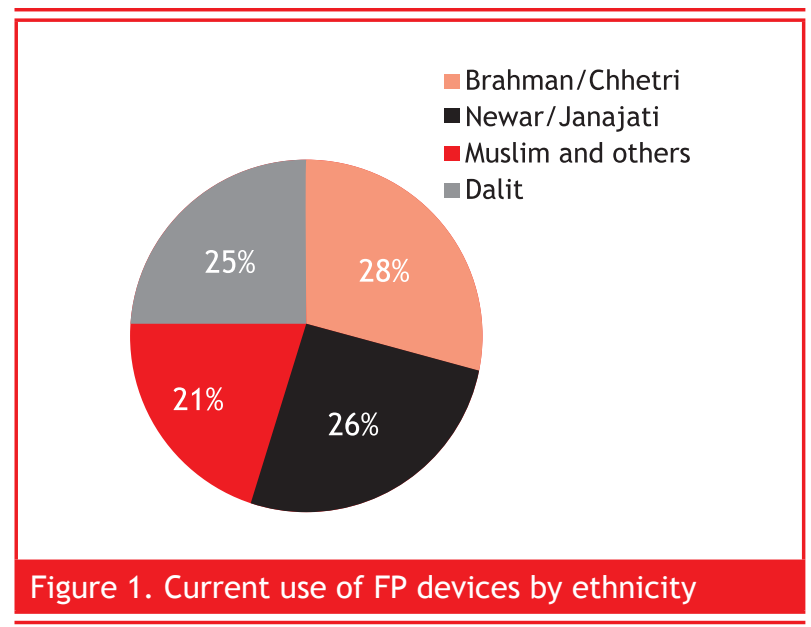

Majority of FP users used depo-provera (53.8\%) followed by condom (22.1\%) and minilap (11.9\%). Condom use is apparently higher in hill (58.5\%). As compared to the males, females have shown higher acceptance to FP contraceptives. 
The success seems mixed, only half of the districts have increasing rates. The CPR rate, as per NDHS 2001 in Nepal, is $38.9 \%$. It has been exceeded in six districts. However, it is on down side in four districts (Solukhumbu, Kanchapur, Dang and Doti).

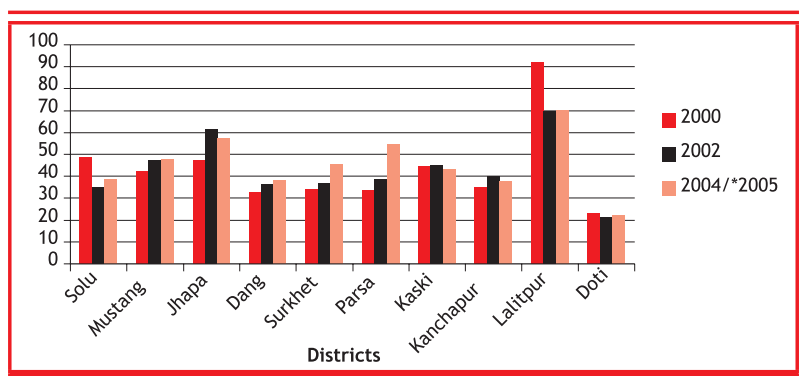

Figure 2. CPR current users as percentage of MWRA

\section{Outpatient Care}

Health facility records show nine out of ten patients visit the HFs. In six out of 10 districts (Solukhumbu, Mustang, Jhapa, Surkhet, Kaski and Doti) OPD new visits seem increasing. In Dang, Parsa, Lalitpur and Doti districts, the trend is reverse. The pace of patient flow seems relatively higher in the mountain districts; Solukhumbu and Mustang.

The study has revealed that the quality of record keeping in the health facilities is poor and in many times, data consistency was lacking. It is also evident that health facility statistics are yet to be utilized in reviewing the services provided by the respective health facility and in planning EHCDS in the facility, district and national levels.

Women interviews and review of health records reveal higher morbidities in the study districts. Mothers reported fever (50.9\%), diarrhea in children (39.8\%), common cold $(23.4 \%)$ and weight loss $(99.8 \%)$ as the main health problems (Table 4).

\section{Table 4. Types of self-reported morbidities}

\begin{tabular}{|ll|}
\hline Morbidity type & Percent \\
\hline Fever & 50.9 \\
Diarrhoea & 39.8 \\
Common cold & 23.4 \\
Weight loss/weakness & 9.8 \\
Injuries & 9.3 \\
Malaria & 8.7 \\
Tuberculosis & 8.5 \\
Others & 10.8 \\
\hline \hline
\end{tabular}

The exit clients reported general health checks (28.8\%), delivery/postnatal (PNC) services (22.1\%), ANC cheeks $(12.5 \%)$ and diarrhea $(10.6 \%)$ as the reasons for visiting health facilities. In household level, treatment seeking was reportedly higher $(87.4 \%)$. These findings are compatible to the HF utilization data over the period $2000 / 2001$ - 2004/2005 in the study districts. On the whole, nine out of ten patients visiting the health facilities were reported as outpatient. The health posts have highest proportion of clients coverage (31.9\%) followed by SHP (24.5\%), District and Zonal hospital (20.9\%) and PHCC (15.9\%).

\section{Child health}

The coverage of DPT 3, Polio 3, BCG and measles are 92.8\%, 93.4\%, 95.2\% and 90.7\% respectively. The DPT 3 and Polio 3 coverage are highest in hills $(95.4 \%$ for each) while BCG coverage is found highest in mountain district $(98.8 \%)$. Terai districts top on measles coverage (97.2\%).

Eight out of ten children have ever visited HFs seeking health services. The purpose of the visits are immunization, treatment of ARI/pneumonia, diarrhea, Skin diseases, worm infestations and general checkups.

The achievements for the period 2000/200- 2004/2005 are mixed. There is a downward trend in BCG coverage in seven districts namely Solukhumbu, Mustang, Jhapa, Parsa, Kaski, Surkhet and Doti districts while it has upward trend in the rest three districts; Dang, Kanchapur and Laitpur. In the same way, in half of the districts, progress on DPT3 appears increasing (Solukhumbu, Mustang, Jhapa, Dang and Lalitpur) and in one district (i.e. Kanchanpur) it is stagnant. The other four districts (Surkhet, Parsa, Kaski and Doti) follow the similar pattern. There is declining trend in DPT 3 vaccination. Achievement on the Polio 3 and measles vaccination also follows same trend.

\section{Table 5. Summary of progress on childhood} Immunization

\begin{tabular}{|lcccc|}
\hline District & \multicolumn{4}{c|}{ Vaccines (2000 - 2005) } \\
& Polio 3 & DPT 3 & BCG & Measles \\
\hline Solukhumbu & $++\sim$ & $++\sim$ & $--\sim$ & +- \\
Mustang & ++ & ++ & -- & +- \\
Jhapa & ++ & ++ & $--\sim$ & ++ \\
\hline
\end{tabular}

Note: ++ Indicates increased trend

-- Indicates decreased trend

$++\sim$ indicates increase with fluctuations

$--\sim$ indicates decrease with fluctuations

+- More or less similar 


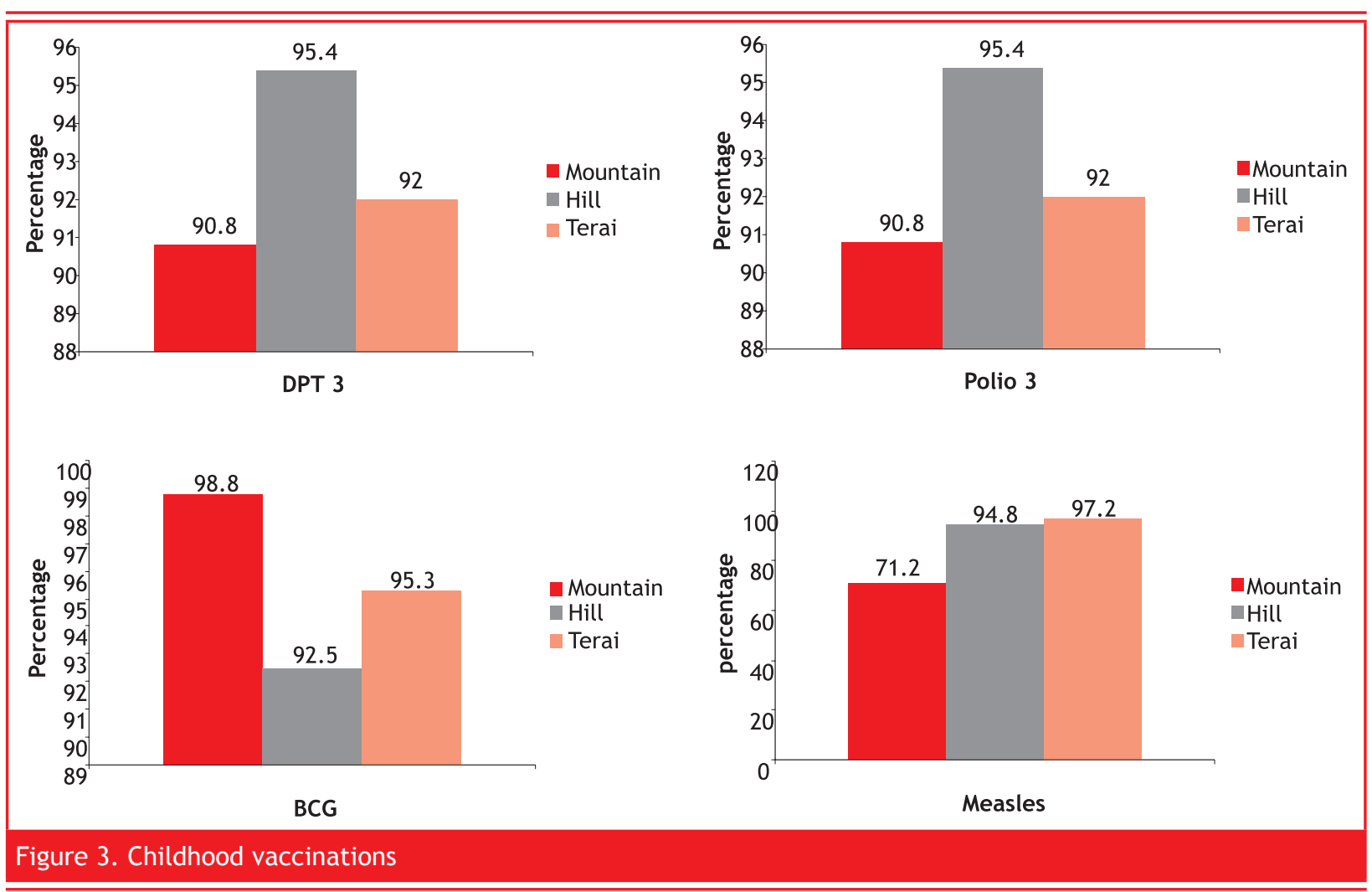

$\begin{aligned} & \text { Table 5. Summary of progress on childhood } \\
& \text { Immunization }\end{aligned}$
\begin{tabular}{lcccc} 
Dang & $++\sim$ & $++\sim$ & $++\sim$ & $++\sim$ \\
Surkhet & -- & $--\sim$ & $--\sim$ & $--\sim$ \\
Parsa & $--\sim$ & $--\sim$ & -- & $--\sim$ \\
Kaski & $--\sim$ & $--\sim$ & -- & $--\sim$ \\
Kanchanpur & $--\sim$ & +- & $++\sim$ & $++\sim$ \\
lalitpur & ++ & ++ & $++\sim$ & $++\sim$ \\
Doti & -- & -- & -- & -- \\
\hline
\end{tabular}

Note: ++ Indicates increased trend

-- Indicates decreased trend

$++\sim$ indicates increase with fluctuations

.- indicates decrease with fluctuations

+- More or less similar

Four out of ten districts (Jhapa, Kaski, Surkhet and Doti) have achieved more than $70 \%$ progress in growth monitoring of under three year children. Solukhumbu district has below $15 \%$ progress. The proportion of severely malnourished children is below $20 \%$ and in almost all districts the rates of childhood malnutrition is decreasing. However the progress is dismal.

ARI among under five children seems on the rise. It is exceptionally higher in two mountain districts $(400 / 1000$ in Solukhumbu and 600/1000 in Mustang) and two Terai districts (700/1000 in Jhapa and 400/1000 in Parsa district). Kanchanpur district, which is also a terai district in the Far Western Region, has nearly 400/1000 ARI cases in 2004/2005. Thanks to the diarrhea control program, it seems successful in containing diarrhea well below $15 \%$ over the year (2000 - 2005), which was $22.8 \%$ in 2001 (NDHS 2001). In the same period, however, one (Lalitpur) out of 10 study districts has increased trend of diarrhea but it is only $6 \%$ in $2004 / 2005$.

\section{Effectiveness and Sustainability}

Skin diseases and gastro-intestinal problems continue to be the main health problems in the districts. Some diseases are specific to ecological regions. For example, terai districts are prone with vector borne diseases and snakebites. Diseases associated with life style are also highly reported, particularly in mountain districts. Women in most of the districts suffer from uterine prolapse, vaginal discharges and postpartum hemorrhage. Married women whose husbands migrate for work have been reportedly under the risk of STI and HIV.

Internal migration due to open conflict in the country has led to high mobility of laborers within the country resulting to new diseases pattern. Similarly, ARI, diarrhea and skin diseases are reported as the common health problems among children. The health service utilization data $(2001 / 2002$ - 2005/2006) depicts general health cheeks $(40.4 \%)$, skin diseases $(9.3 \%)$, headache/fever (7.8\%), APD (5\%), ARI (4.4\%), tuberculosis (3.7\%) and diarrhea as the main reasons behind visiting the health facilities by the patients. 
Service providers from across the districts reported adequate stock of medicines for normal emergency situations. However, for unavoidable disasters and emergencies, the stock would not meet the demand. Lengthy procedural and legal process in bidding of drugs, vaccines and equipment, delay in supply due to lack of road transportation, and absenteeism of service providers seem as the impediments in emergency preparedness.

Immunization, CDP, IMCI and DOTS appear as the most effective service components. Though the community insurance scheme is under piloting, it is informed as one potential approach to address the needs of the disadvantaged groups.

Of the total clients who visited health facilities over the period 2001-2005, 55\% were females. Health services utilization by females seems higher in mountain and hills while in terai more males than females turned to seek health care.

By caste/ethnicity, it was the so called higher casts (Brahmin/Chhetri) who utilized health services at the most $(47.6 \%)$. It is followed by Janajati $(24.1 \%)$, Dalits (17\%) and Muslims (3.6\%).

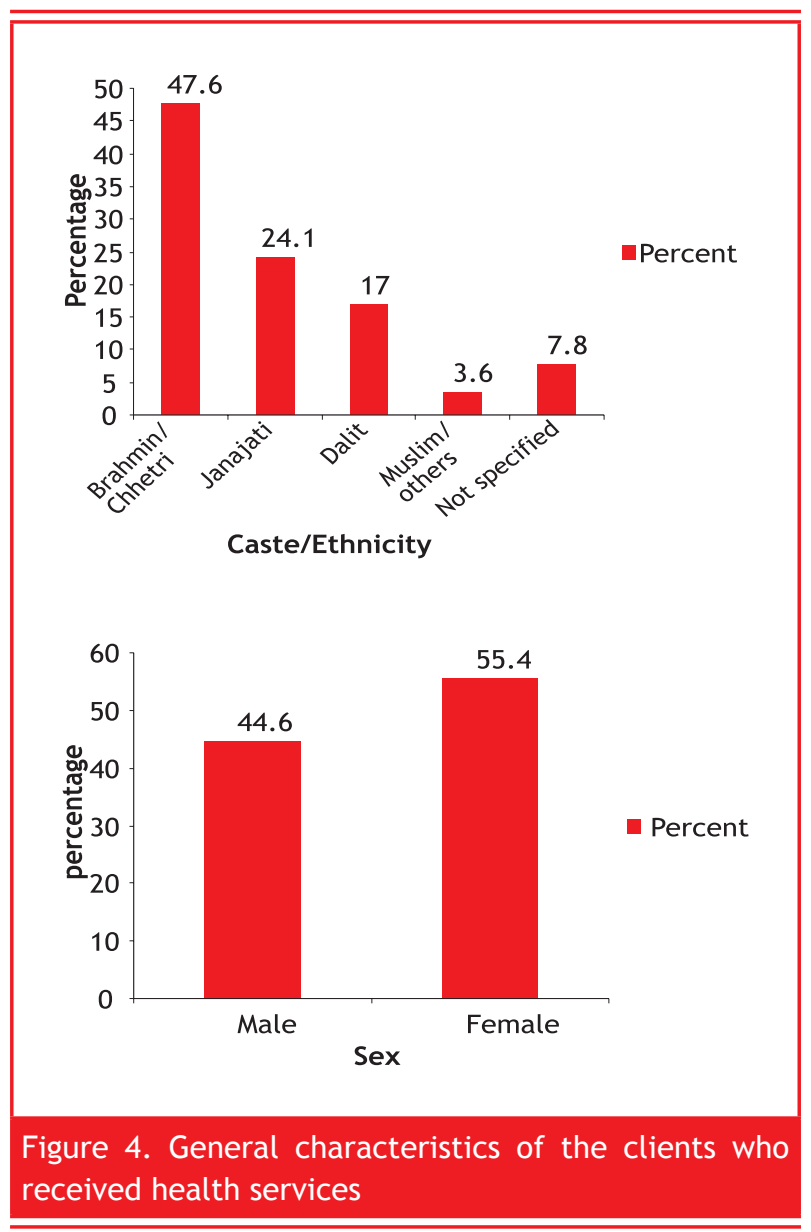

By month, Bhadra (mid August - Mid Sept.) appears as the peak month for client's flow while Baisakh (Mid April - Mid May) witnesses least number of clients. In the same way, children below 14 years have exceeded the other age groups followed by 25 - 29 year's age group.

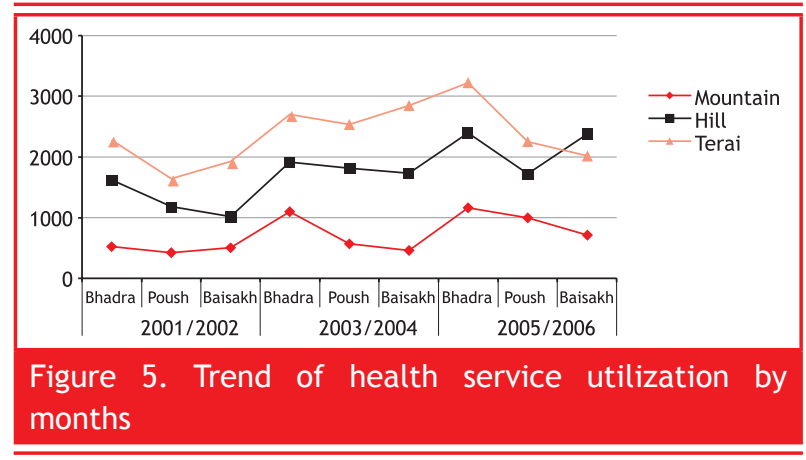

According to type of health facility, health posts in hills have the highest client flow (31.3\%). Among the PHCCs, mountain districts have highest service users as the PHCC have served as an alternative to hospitals. However, in Ayurved centers and SHPs, client flow seems similar in all regions.

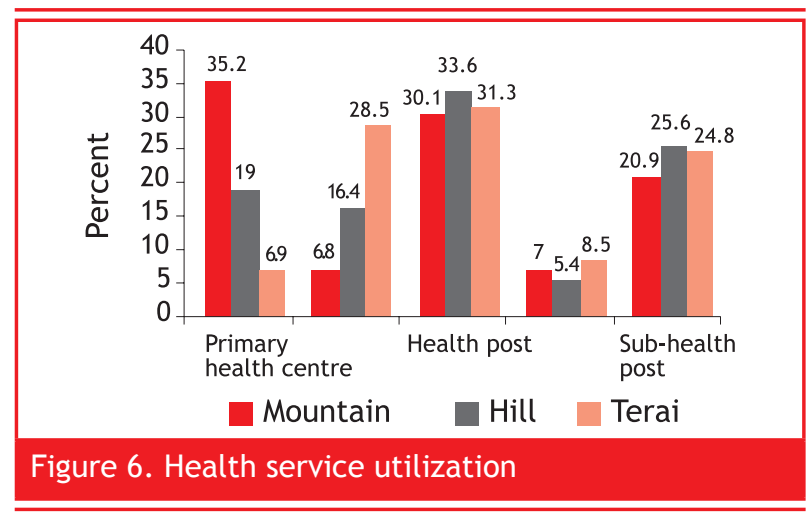

Building on the lessons from the protracted open conflict, Nepal's public health system has adopted a number of approaches and program modalities in health sector. Policy to include disadvantaged groups including dalits, women, disabled and elderly people, increased coverage of the health programs to more remote and pro-poor areas, support to establishing emergency funds and community drugs schemes are the key approach taken. The negative impact of conflict is reportedly lesser in comparison to other sectors.

The study has confirmed presence of a sustained and adequate coverage of health service facilities from central to the VDC levels. Such a visible and well defined organizational set up with different levels of human and other resources ensure organizational viability and longevity. Moreover, there is a functional community support system like HFMCs, MGs, FCHVs and TBAs for the mobilization of local communities. However, motivation 
and performance of these groups has been questioned due to many reasons.

Six out of ten districts (Kaski, Kanchapur, Jhapa, Surkhet, Dang and Lalitpur) SHPs are handed over to the local level. However, anecdotal reveal that despite the positive start up, there is a perception that quality of health services delivered by these decentralized health facilities has not been improved. Lack of support, monitoring and follow up were cited as the reasons behind it.

The public health facilities in Nepal, by and large, depend on public financing. It is notable that PHCCs and hospitals are more relaxed to charge users fees on their services while the HPs and SHPs provide basic services to the grass root people, mostly free of charge.

Various I/NGOs have contributed for increasing coverage and effectiveness of EHCS. However, in the absence of clear policy, they are yet to be accessible to the remote areas. Support from the local VDCs and municipalities for the development of infrastructure, human resource and equipment seem nevertheless important. Very little was done to enter partnership between the private and public sectors.

In order to maintain financial transparency, notice boards and citizen charters (Nagarik badapatra) have been posted in health facilities. However, these are not known, particularly to the illiterate clients. Moreover, there seems lack of a more transparent financial system from the district to the local level and community auditing measures are yet to be introduced.

\section{Equity and Efficiency}

Socio-political, cultural, economic, geographical and institutional factors determine equity while the efficiency is the access product of budget allocation and absorption efficiency, ratio of program and administrative costs, mobilization of local resources, supportive supervision and functional referral system, documentation ad reporting mechanisms, among others. ${ }^{5}$

Physically, $83 \%$ women and $71 \%$ exit clients reported that they have access to a health facility within 30 minute's walk and the rest $16 \%$ women and $14 \%$ exit clients could have reached with in one hour on foot. Access to health facility with in 30 minute's walk in mountain, hill and terai was reported by $66.6 \%, 74.4 \%$ and $69.8 \%$ clients respectively. Similarly, $79 \%$ clients' access of road in mountain is least (4.1\%) followed by hill (44.6\%) and terai $(51.4 \%)$.

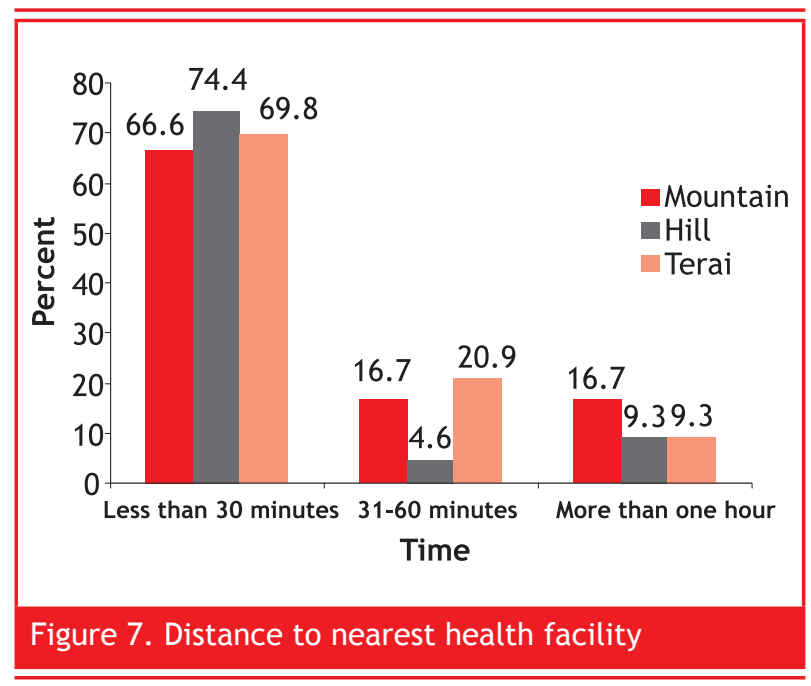

Of the total patients, overwhelming (88.8\%) sought treatment from the health facilities. This tendency was highest $(92.6 \%)$ in hills followed by terai $(88.2 \%)$ and mountain $(80.7 \%)$ districts.

Women's access to PHC/ORC and immunization clinic seems reportedly higher among Muslim in terai (85.7\%), and Brahmin/Chhetri (74.2\%), Newar/Janajati (73.2\%) and Dalits (73\%) have similar access to such outreach services.

More than two third of the women (68.3\%) had access to FCHVs, nearly one-fifth (15.5\%) with MCHWs, 3.8\% with community health promoters and $5.3 \%$ to other health care providers.

Nine out of ten women reported the cost of delivery was managed from their family. The rest borrowed loans (12.2\%) from others, from emergency fund $(0.7 \%)$ and mother groups $(4.15 \%)$.

About three quarters $\mathbf{( 7 1 . 5 \% )}$ of the women were knowledgeable on local FCHVs as $69.9 \%$ in mountain, $67.1 \%$ in hill and $71.7 \%$ in terai could tell name of a local $\mathrm{FCHV}$. It is notable that nearly three quarters of women (73.7\%) could tell at least four ANC visits were necessary during pregnancy. This knowledge appeared highest in hill $(87.5 \%)$ followed by mountain $(70.5 \%)$ and terai (66.9\%).

From the analyses of financial records of a mountain (Solukhumbu), hill (Doti) and terai district (Parsa), it becomes clear that absorption capacity of the district health system is almost over $95 \%$. The administrative costs are below 15\%, on the whole. The trend of administrative cost seems declining. 


\begin{tabular}{|c|c|c|c|c|c|}
\hline Particulars & $2000 / 2001$ & $2001 / 2002$ & $2002 / 2003$ & $2003 / 2004$ & $2004 / 2005$ \\
\hline \multicolumn{6}{|l|}{ Solukhumbu District (Mountain) } \\
\hline Absorption capacity & 78.3 & 77.8 & 84.9 & 89.8 & 92.2 \\
\hline Admin cost against program cost & 16.7 & 15.2 & 14.6 & 14.1 & 14.3 \\
\hline \multicolumn{6}{|l|}{ Doti District (Hill) } \\
\hline Absorption capacity & N.A & N.A & 96.3 & 94.6 & 96.6 \\
\hline Admin cost against program cost & N.A & N.A & 11.6 & 12.1 & 14.7 \\
\hline \multicolumn{6}{|l|}{ Parsa District (Terai) } \\
\hline Absorption capacity & 97.1 & N.A & 97.0 & 98.0 & 94.6 \\
\hline Admin cost against program cost & 14.9 & N.A & 10.7 & 15.1 & 13.2 \\
\hline
\end{tabular}

Lack of timely and supportive supervision was frequently raised by the service providers. Supervision is mostly limited to road heads and its peripheral areas. In remote districts, supervision works were very limited. Most of the service providers opined that there was no opportunity to share learning during supervision. It was also reported that the trend of supervision is declining due to conflict, reduction in budget and lack of follow up mechanism. Similarly in more than half of the D/ PHOs, there is computer facility for documentation and reporting of the health records. However, the system is not fully functional.

\section{Quality of Care}

Interpersonal communication on how and when to take medicines and return to follow ups seem well happening. i.e. by $87.1 \%$ and $60.7 \%$ respectively. However, side effects are communicated at low extent (19.4\%). Women reported preference of home delivery compared to health facility due to lack of privacy and poor facilities.

On the whole, $86.5 \%$ exit clients and $71.9 \%$ mothers expressed their satisfaction over the serviced received from the health facilities. By ethnicity, client satisfaction appeared highest amongst Muslims as $100 \%$ exit clients and $84 \%$ mothers reported their satisfaction towards the health services they received. Level of satisfaction was lowest among the Brahmin/Chhetri as $80.4 \%$ clients and 46.3\% mothers were satisfied from the health services. Almost all women and $70 \%$ exit clients liked the service providers' behavior. Close location of health facility (20\%), good physical facilities and infrastructure $(18.8 \%)$ and treatment efficacy (3.3\%) were the other reasons behind satisfaction.

On the whole, $77.6 \%$ staffs in the hospital are fulfilled. Data from eight districts show only two-third of the doctors (62.7\%) are fulfilled where as only half of the pediatrician, and one third $(33.3 \%)$ of the sister-incharge positions are fulfilled. Eight out of ten staff positions are filled in. However, they are physically present in very limited hospitals only. There is a critical absence of medical doctors in PHCCs (40.9\%). The PHCCs are also poorly staffed with staff nurses (57\%) and lab technicians. Overall three quarter of staff in the sampled PHCCs is fulfilled.

Compared to hospitals and PHCCs, staffs in HPs and SHPs are fulfilled more $(96.3 \%$ in HPs and $89.9 \%$ in SHPs). Seven out of ten (30\%) HAs in HPs and seven out of ten VHWs in sampled SHPs are found fulfilled. Anecdotal from across the districts particularly from Mustang, Solukhumbu, Dang, Surkhet, Kanchapur and Doti revealed critical absence of medical personal in the district hospitals and PHCCs. In Aurvedic facilities also, many posts are found unfulfilled. On the other hand, number of health workforce has not been reviewed for the past many years. The need for review of staff quotas was pertinently raised from terai districts.

Delayed supply of drugs was also frequently reported in hilly and terai districts. Many life saving drugs reach to the health facility near or after their expiry dates. Moreover, the drugs are hardly sufficient for four months. Similarly, many instrument donated by the donor agencies and governments are found non-operational due to lack of maintenance and proper knowledge and skills on handling them. In some districts, even the instructions to use them are written in other languages (Japanese and French languages), which could not be understood by the local health workers.

\section{Inclusion of Marginalized and Disadvantaged Populations}

Though who is disadvantaged and how to measure poverty is not clear in Nepal, dalits, women, ethnic 
minorities and people with disabilities are considered as discriminated groups. In this study, an effort was made to assess status of the households by food sufficiency and essential household commodities. In addition women's involvement in groups and service seeking by the disadvantaged groups have also been studied. The study findings reveal that one-third of the households have no foods even for three months and seven out of ten households have food available for less than nine months.

The household durables such as electricity, Radio, gas stove, television, telephone and bicycles were available to $71 \%, 63.8 \%, 15.9 \%, 23.6 \%, 13.4 \%$ and $36.5 \%$ households respectively. By caste and ethnicity, more dalits (33\%) compared to other castes and ethnicities have no access to such durables. In the same way, access to these commodities, except television seem higher in terai districts followed by hill and mountain districts.

More than one third of the women interviewed were found involved in mother groups. The participation in these groups was highest in terai $(52 \%)$ followed by hills $(29.8 \%)$. Besides, women were also the members of CFUGs (6\%), and farmer's groups (6\%). From the perspective of caste and ethnicity, it was the Brahmin/Chhetri who were mostly covered (53.1\%). It was followed by Newar and Janajati (38.8\%). In HFMCs, more Newar and Janajatis were included (42.9\%).

There was a perception among service providers and recipients that poor, marginalized and dalits have been focused in order to increase their access to public health services. They opined that there was no any discrimination and biases on the part of providers on the basis of ethnicity, sex or regionality of the clients. Health records show higher utilization among females and children. It again indicated vulnerability of these groups. It was confirmed that public health services were mostly used by the poor and women and dalits due to low cost of the services and easy access. It was frequently reported that rich and educated ones prefer high services provided by the private sector. It was reported from the health facilities that disadvantaged groups are exempted service cost from 15 to $50 \%$ and also get services free of cost. However, very few hospitals have emergency and poor fund to support the disadvantaged groups. Even in health facilities having this provision, the definition of poor and disadvantaged groups is unclear. As a result, exemption of fees for the services received from a facility rests on the discretionary decision of the in-charge.

\section{DISCUSSION}

The study revealed that a top down approach has been in practice where in the health targets are handed down to the district and below levels from the DoHS. Due to such practices, targets do not match with the realities at the facility level. The number of expected pregnancy, number of under one and under five children to be served do not match in VDCs having high mobility of people. As a result, some districts inflate $10 \%$ values to meet their targets. Moreover, indicators of the districts having five year plans seem incompatible to the DoHS targets. Lack of knowledge or very poor understanding of five year plan, PRSP, MDG, and NHSP indicators has also been reported frequently across the districts. It shows gaps in the localization of health sector plan and programs.

The health services delivery is yet to be made responsive to the ecological and district specific health problems. Dissemination of health sector strategies at various levels is equally crucial.

It is encouraging to note that achievement on TT vaccination, ANC checks, delivery attendance by skilled personnel, FP use rate, childhood vaccinations, control of diarrhea and malnutrition and OPD new visits show increasing trend over time but the progress is slow in pace. The pace of increment is lowest among dalits and in mountain regions. Hence, women and dalits need to be specially focused while planning health programs so as to include them within the mainstream of health services.

The SHPs and HPs have covered highest proportion of population in need of basic health services. It is highly necessary to ensure sustained delivery of priority health services through them. Improving the coverage and quality of services in the PHCCs and hospitals seems equally important.

Childhood immunization including $\mathrm{IMCl}$, CDP, DOTS and emergency fund has been reported as the most effective service components. There seems a seasonal variation in client flow in the health facilities. It is something that should be looked at in future. PHCCs and few Health posts in hills and mountain districts have served as key service outlets but they seem poorly equipped. Such disparities should be taken into account while delivering drugs and other supplies to the health facilities.

In the absence of clear policies, guidelines, and support and follow up mechanisms, the health facilities handed over to the communities have yet to improve the quality of services. The hospitals and PHCCs seem more relaxed to charge user fees than by the S/HPs. The S/ HPs expressed risk of confronting with the public to put on user fee to the basic services with poor quality. This again invites more input and support to the S/HPs.

The health sector has received tremendous support from the local VDCs, DDCs and I/NGOs but these are not regular 
and accessible in all areas. The role of private sector has not clearly been defined. Therefore, it is necessary to identify areas of potential partnership with private sector and enter into partnership for the health promotion activities. Inter and intra-sectoral coordination for health is also important for the sustainability of EHCS. Supportive supervision with a functional monitoring and documentation and development of an HMIS that incorporates services provided by I/NGOs and private sector is urgently needed.

Despite increase in self-reported access, still many women do not attend health facilities due to lack of knowledge of PHC/ORCs, special health camps and local FCHVs. Hence, raising awareness about the health services availed by the health facilities through enhanced IEC activities is highly necessary.

The absorption capacity of the district health system seems above $95 \%$. The administrative cost is below $15 \%$, with a declining trend. However, further studies are necessary so as to ascertain cost effectiveness of the EHCS.

Acute shortage of service providers, particularly medical personnel in the hospital and PHCCs was reported. The main reason for the absence of health workforce was reported as lack of proper supervision by the subordinates, absence of periodic and timely review of positions by ecological regions and population density. Therefore, a functional supervision, decentralized to the local bodies where possible, and timely review of health workforce is suggested.

\section{CONCLUSION}

In the absence of staff with proper knowledge on handling and maintenance, important equipments seem nonfunctioning in many health facilities. A special attention is to be given to train staff on handling of equipment and ensure proper storage mechanisms in place. Health sector services are still to be made more inclusive in light of the local needs and linked with doable safety nets.

\section{ACKNOWLEDGEMENT}

I would like to acknowledge NHRC for entrusting me to lead this study and publish its fey findings.

\section{REFERENCES}

1. Ministry of Health and Population. Nepal Health Sector ProgramImplementation Plan, 2004-2009. Kathmandu: Ministry of Health and Population; 2004.

2. Ministry of Health and Population. Health Sector Strategy: An Agenda for Reform. Kathmandu: Ministry of Health and Population; 2004.

3. MoHP/NEW Era/ORC Macro. Nepal Demographic and Health Survey. Kathmandu: Ministry of Health and Population; 2001.

4. Ministry of Health and Population. Annual Report 2003/4. Kathmandu: Ministry of Health and Population; 2003.

5. Thomas D, et al. Evaluation of increasing access component. NSMP/options 2005. 